\title{
Limits to Growth and Achievement of Global Sustainability ${ }^{1}$
}

\author{
Arkady Ursul \\ Doctor of Philosophical Sciences, Professor, Lomonosov Moscow State University \\ (Moscow, Russia) \\ E-mail: ursul-ad@mail.ru \\ ORCID: 0000-0003-2643-5558 \\ Teodor Tirdea \\ Doctor of Philosophical Sciences, Professor, \\ State University of Medicine and Pharmacy "Nicolae Testemitanu" \\ (Chisinau, Moldova) \\ E-mail: tirdea_teodor@mail.ru \\ ORCID: 0000-0002-8688-0672
}

\section{Tatiana Ursul}

\author{
Doctor of Philosophical Sciences, Professor, \\ National Research Technological University "MISiS" \\ (Moscow, Russia) \\ E-mail: ursult@mail.ru \\ ORCID: 0000-0002-4520-9487
}

In the work notes that the preservation of the planet's biosphere and its ecosystems (especially mountain) is one of the main goals of the transition to such a global process as sustainable development. Moreover, not only the goal, but also with the condition of its realization, is the natural foundation on which sustainable development should be realized as a successively unfolding new socio-natural process. The concept of planetary boundaries is discussed, which concretizes the concept of "the carrying capacity of the biosphere" and defines "a safe working space for humanity", that allows it to survive and further develop progressively. The concept of planetary boundaries establishes a corridor of global environmental security, within which the biosphere is minimally destroyed by anthropogenic activities.

Keywords: biosphere, carrying capacity of ecosystems, mountain sustainable development, natural security, planetary boundaries, safety, social constraints, sustainable development

Received: February 23, 2018; accepted: April 10, 2018

${ }^{1}$ The work is supported by Russian Science Foundation grant No. 18-18-00426 "Limits to growth" in the $21^{\text {st }}$ century and the role of science in overcoming them."

(C) Ursul, Arkady, 2018

(C) Tirdea, Teodor, 2018

(C) Ursul, Tatiana, 2018 
Philosophy and Cosmology, Volume 21, 2018: 42-51

DOI: $10.29202 /$ phil-cosm/21/5

\section{Introduction}

Reports of the club of Rome, or otherwise associated with the development of the idea of limits to growth, has contributed to the development of global studies and the formation of the concept of sustainable development (SD). SD model must first be created with the help of science and then implemented by managerial decisions and actions at the local, regional, national, supra-national and planetary levels. The role of science should be significantly strengthened in the process of movement towards a sustainable future, but science should "turn" to the problem of global transition to sustainable development.

The concept of SD was emerged and actively developed through the last decades. The necessity of introducing of this new concept is primarily associated with the need to study the negative effects of global processes and growing global problems, especially environmental problems. The global ecological crisis of anthropogenic origin takes on a planetary scale and threaten the existence of humanity and life on the Earth. Modern humanity lives now in the status and in process of the so-called unsustainable development - historically a type of evolution of civilization and its interactions with nature leads not only to the prosperity and progress, but also to the multiplication of the dangers of anthropogenic global disaster and even the destruction of civilization. Moreover, negative trends have begun to dominate over the positive and alternative way of civilization evolution, reducing the probability of the risk of global catastrophe, is seen only in the transition to a sustainable development path.

In terms of the multiplying of global challenges and threats it is necessary to move from emergency and other negative consequences of anthropogenic activities to prevent disasters and for preventive and proactive measures, and suggests further movement toward global sustainability. When negative impacts were local (or, in some cases, even regional in nature), it was possible to eliminate their effects, albeit with huge economic losses. However, in the case of the global scale of possible disasters, they should only be prevented, which leads to a different view on the temporal characteristics of the activities of all civilization.

In case of ecological or other planetary catastrophe, its consequences will be impossible to repair for no one [Bostrom, 2008]. The larger the disaster, the harder the struggle with its negative effects on humanity and therefore a means of global problemssolving, reducing the negatives of globalization, global crises and cataclysms, in principle, should be preventive and not "left behind" — as practiced at the local scale liquidation of consequences of emergencies and disasters at the present time. The international community is obliged to foresee the limits of evolution, threats and challenges and proactively create models and scenarios of possible future using different methods of the priority activities for its sustainable development.

After the UN Conference on Environment and Development (UNCED) in 1992 in Rio de Janeiro, the world community has set a goal of transition from natural to sustainable development as the fundamental way to the survival of civilization. Under sustainable development, which should be rationally managed on a planetary scale, is understood to be the most appropriate and safe type of social and socio-natural evolution, aimed at the preservation of civilization and biosphere, their coexistence and coevolution.

The book "Our Common Future", known as the report of Gro Harlem Brundtland, substantiates the necessity of transition to SD that was the definition of the concept of SD. It 
was addressed to the future: "Sustainable development is development that meets the needs of the present, does not compromise the ability of future generations to meet their own needs" [Our common future, 1987: 59]. Here, in fact, formulated the main goal of the transition to sustainability - survival and the survival of mankind on the uncertain future for a long time.

The preservation of the biosphere and coevolution with her civilization will create the basic conditions and perspectives that will lead to a completely new system "society nature" that implements sustainable development strategy that will ensure our common future on the planet, and a cosmic perspective - and beyond. Preservation of the biosphere of planet Earth is one of the main goals of transition to sustainable development. Not only purpose. Its implementation is the foundation on which sustainable development should be established as sequentially unfolding new global process. The most acceptable scenario for the future of our planet and living of mankind on it involves the preservation of the biosphere as the natural basis of existence of all life and intelligent.

It includes further strategy of evolution of intelligent matter, including further neuroevolution and wide development of extraterrestrial space [Bazaluk, 2013, 2015, 2016].

\section{Limits to growth and sustainable development}

The concept of limits to growth have been put forward in the reports of the club of Rome in the early 70-ies, although it in one form or another, thought Montesquieu, Condorcet, Malthus, etc. This concept is even considered one of the basic concepts of globalistics, because it gives an idea of the finiteness of the size of the planet, its resources and conditions for the existence and future evolution of all mankind.

The concept of limits to growth have been put forward in the reports of the club of Rome in the early 70-ies. According to this concept, the finite size of the Earth and the limitations of its natural resources with fatal inevitability leads to the existence of the limits or the borders of a future socio-economic development. For the first time this concept was formulated in 1971 by George Forrester in "World Dynamics" [Forrester, 2003] and in the next year publication "Limits to growth" [Meadows et al., 1991] prepared by the group of scientists headed by Dennis Meadows. It became clear that if current trends of socio-economic development will continue in the $21^{\text {st }}$ century it will be a global human crisis, and may be even planetary catastrophe. These and other reports (forty) of the club of Rome has contributed to the development of global studies and the formation of the concept of sustainable development. After these reports, it became clear that the vulnerability of ecological conditions and the finite size of the planet Earth, its limited natural resources will inevitably lead to the existence of the limit of growth of material production and population.

Project prepared under the supervision of Meadows, was highly appreciated and attracted wide attention to the activities of the club of Rome and initiated the study and awareness of the need for solutions to global problems, their causes and possible consequences. In result was created and adopted by the UN strategy for sustainable development (SD), which should implement the global community. It was to some extent an adequate response to the old concept of limits to growth.

The existence of certain "limits to growth" is not only a limitation of extensive growth, but also a prerequisite for further progress in a new direction. The limits to the progressive evolution of civilization is often caused by restrictions determined by the fundamental laws of nature and other factors, for example, the limitations of our biosphere and the planet as a whole. In addition, this is the achievement of a world community for socio-economic development on a global scale. This leads to aggravation of the socio-natural contradiction 
between the growing needs of humanity, the limitations, and even the inability of the biosphere to provide these needs, especially for future generations.

It is important to identify the most significant constraints and limits to growth and development, to find out what restrictions lead to new paths of progress in general and which significantly inhibit lead to degradation and disasters. In many cases, implemented a variety of development paths, stopping in one direction, a progressive development can continue in a different "dimension". History of anthropo-societal genes confirms that the emergence of certain "limits" for extensive growth served as a pretext and the reason for the transition to new ways of evolution. If there were no limits (which are extensive) for appropriating economy, humanity is likely to be degraded in the same form as the existing tribes "sympoliteia Paleolithic". The output of the food and the demographic crisis of the upper Paleolithic were found in the transition to a producing economy.

Sustainable development is viewed as a new form of a global civilizing process, enabling the resolution referred to socio-natural contradiction between the growing needs of humanity and the limitations, or even the inability of the biosphere to provide these needs. The global transition to SD is now recognized not only as a new form and strategy of the development of mankind to ensure its permanent evolution, but as a new co-evolution method of interaction between society and nature. The establishment of a global sustainable world is seen in the context of achieving such a state (and process) of civilization and its interaction with nature, which is realized in such a planetary scale and in the longer term will be related to space exploration.

That is why the concept of SD in the preservation of the biosphere has become the critical goal, the implementation of which depends the success in the transition to this type of development. In this regard, SD is largely associated with biospherically development of mankind (and to a certain extent, low-carbon and low-emission, bearing in mind the terminology of the new climate agreement reached in Paris).

Reports of the club of Rome, or otherwise associated with the development of the idea of limits to growth, has contributed to the development of global studies and the formation of the concept of sustainable development. In this direction abroad, work is continuing to identify or limits in nature and in society.

\section{Socio-natural limits: planetary boundaries and social restrictions}

In 2009 there was proposed the concept of planetary boundaries (planetary boundaries) by the Swedish scientist Johan Rockstrom and Australian Will Steffen with cooperation with more than two dozen scientists [Rockström et al., 2009]. The concept is concretized the already mentioned concept of "carrying capacity of the biosphere". It appeared on the crossroads of research from the perspective of the idea of "limits to growth" club of Rome and the planetary ecological capacity of human activities (carrying capacity of the biosphere).

The mentioned authors identified nine planetary boundaries, although other scientists say several more such boundaries, for example, ten or eleven, and has clearly traced the tendency to increase their number. Nine planetary boundaries that are dependent on human activities, include: climate change, extinction of species, the cycles of nitrogen and phosphorus, chemical pollution, acidification of the oceans, ozone depletion, global freshwater use, the ratio of acreage to total land area, the concentration of particulates in the atmosphere. A number of these indicators have already received preliminary quantitative expression, whereas the remaining due to lack of reliable information is determined only qualitatively. 
Planetary boundaries, in fact, is a biosphere restriction of economic and other activities of mankind, who will give it the opportunity to prosper and grow for centuries, and even millennia. Identified nine socio-natural processes, which have boundaries until they are crossed, be a safe space for human development. The concept of planetary boundaries establishes a corridor (area) of global environmental safety, within which the biosphere is minimally destroyed by anthropogenic activities.

For some of them (loss of biodiversity, climate change, and human interference in the nitrogen cycle) level of safety significantly exceeded. It turned out that by these parameters greatly civilization went beyond the safe zone, so it is urgent to begin to move in the opposite direction. Other remaining "planetary boundaries" of humanity is still kept within permissible values, but fast approaching it. The violation of one or more planetary boundaries may be harmful or even catastrophic due to the risk of crossing thresholds. They can cause nonlinear, can be very sharp change in environmental systems on a planetary scale. Therefore, crossing these boundaries does not pose quite predictable, but almost certainly unpleasant consequences that could threaten the future of civilization.

It is important to pay attention to the rate of change of these indicators: so the decline of biodiversity is a hundred or even a thousand times faster than, for example, during the last mass extinction, the disappearance of the giant reptiles. So, increasingly, is about a new - the sixth mass extinction of biota are influenced by anthropogenic activities. Assessing the speed of development of modern civilization and the evolution of the biosphere information on the characteristics, some scholars emphasize that the speed of this latest seven orders of magnitude slower than the rate of accumulation of socio-cultural information [Arsky et al., 2003].

The international organization Oxfam rightly proposes to add the concept of social boundaries to the concept of planetary boundaries [Raworth, 2012]. As it is noted in this work, today the main reason for negative changes of the planetary boundaries is excessive consumption of goods and services by $10 \%$ of the wealthiest people in the world. Their needs are provided by companies manufacturing all sorts of benefits for this population. $10 \%$ of the richest people in the world accounted for $57 \%$ of world income. At the same time, the poorest 20 percent is only $2 \%$. The huge gap in income levels, lack of gender equality, and the difference in the rights of citizens means that millions of people live at the lower boundary of social indicators. Almost 900 million people are hungry; and 1.4 billion people live on less than $\$ 1.25$ a day, and 2.7 billion people do not have the ability to cook food in normal conditions. Excessive consumption of resources by $10 \%$ of the richest people in the world deprives billions of people with more modest requests, and the reserves of such resources are not limitless. It is necessary to stop the hardships of the people, but stay within reasonable limits when using natural resources.

\section{Conceptual-symbolic modelling of limitations achieving global sustainability}

The formation of the new strategy of SD means a gradual connection in a single selforganizing system of economic, environmental and social spheres (sometimes referred to as the "SD-triad" or the triangle). Probably, with the formation of the "SD-triad" it was necessary to start; these three areas of global activities are important as their relationship, but now it became apparent that this was no longer enough. The need to expand the subject field of motion study to global sustainability and vision of the concept of SD fully integrated and thus more effective in its implementation are appeared. 
The concept of SD cannot and should not be limited to "SD-triad" relationship of ecology, economy and social sphere, at least in its current format. These three "target of measurement" of a future transition to SD should be significantly expanded, making the global "space of movement to SD" in the evolutionary-branching n-dimensional phase space, where they will receive additional directions and dimensions, involving the development of new models for the future of civilization process. We have to make model of SD based on a virtual theoretical view of the future of the global world and to go towards the inclusion of other visions of the future, which has not yet received such wide recognition and official registration with the UN.

The transition from a model of unsustainable development (USD) to the model of SD as an overarching management process can be symbolically represented as the imposition of major restrictions on naturally (spontaneously) occurring socio-economic process, which should reduce its negative impact on society and nature [Ursul, 2006]. Kind of restrictions are placed on economic development, which cannot and should not mainly be deployed for extensive trajectory. In order to organically fit in SD, the economy should move to intense and biospherically path of development, when the growth of efficiency will not be at the expense of the quantitative factors and the expansion of space activities, but at the expense of qualitative factors and sources.

Modern economo-centric model USD substantially symbolizes the concept of economic efficiency, expressing the ratio of performance $(\mathrm{R})$ to the cost $(\mathrm{C})$ that determines economic efficiency (E):

$$
\mathrm{E}=\mathrm{R} / \mathrm{C} .
$$

Moreover, the increase of economic efficiency in the forms of profit, productivity, profitability, and other related concepts of economy expresses the motive and interest of activity of subjects of market relations.

The transition from NSD to the model of SD as an overarching global managed process symbolically can be represented as a superposition of the basic restrictions naturally (spontaneously) occurring in market process. Such restrictions are necessary to overcome emerging of social and socio-natural limits and boundaries to continue the safe prosecution of the progressive development of civilization. This implies a decrease in relevant negative consequences for society and the biosphere. Using further the expression of economic efficiency (E), we note that the methods of achieving it does not remain the same as in the current model of development.

Moreover, certain restrictions are imposed on process of economic dynamics as overcoming the historical stereotypes of exponential growth, leading to the "limits to growth". For organic adaptation in a future model of SD, the economy needs to shift from extensive to intensive way of evolution. In other words, the efficiency gains will not go through the quantitative factors and the expansion of space - field activities, but at the expense of qualitative factors and sources. "Sustainable economy" is not just "biospherical economy", but also the economy that have fallen on the path of intense innovative development that significantly reduces the quantitative parameters as the master of natural resources and waste, contributing to a more organic introduction of other management constraints, both in environmental and social spheres.

Therefore, ecologically safe intensive economy is the economy in conditions of global and other constraints and maximize the use of qualitative factors and sources of development 
(which corresponds to the imperatives of SD). Greatly simplifying, it can be expressed as follows:

$$
\mathrm{SD}=\mathrm{E} \cdot \mathrm{B} \cdot \mathrm{S}
$$

where B - natural-biosphere limits of the human impact on the environment (which creates the possibility of preserving the biosphere), S - the aforementioned "planetary boundaries" and social limitations that need to be implemented in the global system "man society" and other internal social relations. Introduction of symbols B and S tells about going beyond of economic relations in the wider (institutional) space - environmental and social, i.e. socio-natural system. Biosphere constraints in the process of interaction between nature and society, we put first in the formula (2), since it is through their awareness and the concept of $\mathrm{SD}$, although the role of social factors (especially social justice) were identified much earlier.

Social limitations arise from the necessity of survival and preservation of humanity (anthropocentric factor of socio-natural systems) as a whole and only apply to the system "man — society", "society — humanity". Among the social (intra — and inter-social) relationship the first place belongs to social (distributive) justice (J) as the consistency (ratio) of contribution of human activities $(\mathrm{CH})$ to the received benefits $(\mathrm{BF})$ in combination with an equal distribution of basic goods (e.g., rights and freedoms of the individual, environmental living conditions, etc.):

$$
\mathrm{J}=\mathrm{BF} / \mathrm{CH} \text {. }
$$

Equal treatment of all members of society, the distribution of basic goods that meet vital human needs, must from the point of view of SD spread to all of the community of people now and in the future (for an indefinitely long time).

Biosphere limits (B) shall be determined based on the need to ensure the sustainability of the biosphere and its natural ecosystems functions regulation and stabilization of the environment (i.e. the biosphere is accepted, not the resource model of the world). These constraints consist of environmental and natural resources components as the imperatives of "sustainable" activities. Natural resource imperatives are in environmental sustainability (ES), which is achieved in the way of gradual replacement of the use of non-reproducible resources (NR) to repeatable resources (RR). This can be symbolically expressed their attitude, expressing the degree of sustainability of environmental management:

$$
\mathrm{ES}=\mathrm{RR} / \mathrm{NR}
$$

With the help of coefficient (4) can be measured by the percentage of replacement of non-reproducible resources reproducible (the degree of adaptability of the strategy of intensification of economic activities).

Ecological component in the interaction of society and the biosphere expresses the function of environmental protection and presented in the formulas explicated to ensure environmental safety (although this significantly reduces the environmental component in the concept of $\mathrm{SD}$ ). Because the environment (in this case the social environment) encompasses a variety of aspects of the relationship between society and nature; and in this sense, environmental management is also included in environmental attitudes as a socio-natural interaction. 
However, the management expresses in the most part an attitude that is directed away from nature to society, since natural resources are taken from ecosystems and are involved in the economic sphere. In the social ecology (and other environmental disciplines where the central member (subject) of interaction of a person and humanity) focuses on the problems of environmental security as social actors, and ecosystems. In this sense, the concept of bearing (economic) capacity of the ecosystems formulates the permissible limit human impacts and focuses (though not explicitly) in search of more rational ways of nature as a stable (and thus more rational) management of natural resources.

Environmental safety can be symbolically presented in the form of the law of requisite variety (W. R. Ashby). In accordance with this law, the ecosystem will be ensured environmental safety, if the interaction of the central member with the external environment (or external environment) will appear the mediator (regulator), a variety of which can handle a variety of disturbing (negative) impacts (e.g. wastewater treatment plants).

Symbolically this can be written as follows:

$$
\mathrm{ES}=\mathrm{MS} / \mathrm{DT}
$$

where DT — the degree of threat, which can be expressed in one way or another measurable unit (for example, a variety of negative impacts), and MS - a measure of safety of the object, expressed in the same units. The degree of safety may be identified by the appropriate factor, without which equal to one if all threats protection (which correspond to the controller of W. R. Ashby) is verified and will be less if the negative effects are held to an object of environmental safety (which may be nature and people, society). Thus, biospheric constraints are expressed using the ratio of environmental safety, without the factor of sustainable nature management.

So environmental safety is a shared security as a central member of the ecosystem and its environment, suggesting their co-evolution relationship. Priority is given internally to the central member of the ecosystem (human, society) that exists at the expense of the environment, determining to some extent the degree of its degradation. Therefore, in accordance with the principles of synergetics, we can speak only about the reduction in the degree of degradation, not a complete cessation, as it will lead to a degradation of the central member of the ecosystem.

Moreover, it should be in mind to provident only ecological but any other kinds of safety, since the SD should be safe in all respects and activities; otherwise, it will not be a safely-stable. This is an acceptable degree of protection or other methods of conservation of nature (quality) of the object, which reduces the negative (harmful) impacts to acceptable to continue the development of the level. As a result, "SD formula" in our simplified case looks like the following:

$$
\mathrm{SD}=\mathrm{R} / \mathrm{C} \cdot \mathrm{BF} / \mathrm{CH} \cdot \mathrm{RR} / \mathrm{NR} \cdot \mathrm{MS} / \mathrm{DT}
$$

This expression shows that the transition from NSD $(\mathrm{R} / \mathrm{C})$ to the model of SD associated with the inclusion of means to ensure social justice $(\mathrm{BF} / \mathrm{CH})$, sustainable management $(\mathrm{RR} /$ NR) and safety (MS/DT), which includes ecological safety.

The presence of those or other components in the "SD formula" (6) would show "weak" or "strong" sustainability in the course of movement from the model of the NSD to the model of SD. The "weak" sustainability means the connection to the economic efficiency of any one 
of the other model components SD, or the inclusion of all these components, but each of them in varying degrees. Most "strong" sustainability involves the inclusion of all components with the maximum possible values of their variables, which is real only in the distant future (at the level of the future of the noosphere). The transition from "weak" to a "strong" global sustainability - this is the real process of transition to SD, which combines at the same time as components of model of NSD (which dominate) as SD model (components and their value should increase over time).

One of the major problems that connects the unsustainable present and a sustainable future is understanding that they need to unite into a single unified system, overcoming the civilizational gap in time. The essence of the transition from unsustainable to sustainable development - in the dominant trend of a decrease in the degree of restrictions and limits, challenges and dangers, including socio-environmental nature, threatening the positive dynamism of civilization.

\section{Conclusion}

At the $70^{\text {th }}$ General Assembly of the UN Summit on sustainable development in September 2015, we adopted a new Agenda for sustainable development, which includes 17 global sustainable development goals (SDG). According to the former leadership of the UN, the adoption of an official document "Transforming of our world: an Agenda for sustainable development for the period till 2030" [Transforming of our world, 2015], marks a new historical stage of transition entire world community to the SD. The SDG continued as the targets of all previous UN documents for study, and the Millennium development goals (MDG), which has been identified as a priority of eight international development goals that were adopted by the States members of the United Nations in 2000 and was mostly completed by 2015 .

The transition to sustainable development in its target form will contribute to the resolution of the main socio-natural contradiction between the growing needs of the world community and the inability of the biosphere to provide these needs [Ursul \& Ursul, 2017]. Sustainable socio-natural development will become more comprehensive, global and the safest type of socio-economic development.

The development of civilization will be safer in all respects if it is implemented in the form of a broad understanding of SD, which implements safety on the necessary and sufficient level for the further preservation of mankind. This provision focuses not only on protection but also on the forms of security that are associated with a faster action, with the formation of development in the most safe (safety is provided through pregressive development). Of particular importance is the preservation of the biosphere, which recently found its expression and concretization of the concept of planetary boundaries.

Now it is important to transfer the idea of seeking limits to growth already in the concept and strategy of sustainable development, to see what prevents its implementation, present the obstacles and difficulties as the new limits for the progressive evolution of humanity in a "sustainable direction". It concerns not only and not so much to finding of new limits to current patterns of unsustainable development, and to a large extent and the formed model of sustainable development. Meadows has already paid attention to it in the book "The limits to growth. 30 years later", and believed that it is not too late to go on the path of sustainable development by formulating a number of limitations for this type of development [Meadows et al., 2008]. 
In the future, we may talking about "transformation" in the interpretation of global sustainability. It is, in fact, a new stage of vision of "sustainable revolution", since the first can be considered as the adoption of the concept and the strategy of transition from the current development of civilization to the future of global sustainability. This is a permanent problem and the incompleteness of the concept of SD it is important to recognize and account for in the further practical activities. Significant adjustments will have to be already formed in the narrow concept of SD and expand it, primarily through the priorities of most important to implementation of a more systemic conception of SD.

\section{[L] References}

Arsky, Yury, Victor Danilov-Danilyan et al. Environmental problems: what happens, who is guilty and what to do? Moscow: Publishing house MNEPU, 1997. 329 p. (In Russian).

Bazaluk, Oleg. Theory of Evolution. Philosophy and Cosmology. Vol. 15, 2015: 25-33.

Bazaluk, Oleg. The Basic Postulates of the Universal Evolution Model "Evolving matter". Philosophy and Cosmology. Vol. 14. 2013: 11-20.

Bazaluk, Oleg. The Theory of Evolution: From a Space Vacuum to Neural Ensembles and Moving Forward. Cambridge Scholars Publishing, 2016. — 170 p.

Bostrom, Nick. Global catastrophic risks. Oxford: Oxford University Press, 2008.

Forrester, George. The global dynamics. Moscow: AST. 2003. 384 p. (In Russian).

Meadows, Dennis, Donella Meadows, Jorgen Randers, and William Behrens. The limits to growth. Moscow: Publishing house of the Moscow University. 1991. 208 p. (In Russian).

Meadows, Dennis, Donella Meadows, and Jorgen Randers. The limits to growth. 30 years later. Moscow: Publishing house "Akademkniga", 2008. 344 p. (In Russian).

Our Common Future. World Commission On Environment and Development. Oxford: Oxford University Press, 1987.

Raworth, Kate. Security and justice for mankind. If we live by the model "rescue"? Oxford: Oxfam House. 2012.

Rockström, Johan, Will Steffen et al. A safe operating space for humanity. Nature. 461, Sept 24. 2009: 472-475.

Transforming of our world: the 2030 Agenda for Sustainable Development. https:// sustainabledevelopment.un.org/content/documents/21252030\%20Agenda $\% 20$ for\%20Sustainable\%20Development\%20web.pdf (accessed 17.01.2018).

Ursul, Arkady. A conceptual model of sustainable development. Ecology of urbanized areas. No. 2, 2006: 34-46 (In Russian).

Ursul, Arkady, and Tatiana Ursul. New Goals of Sustainable Future. Philosophy and Cosmology. Vol. 18, 2017: 37-50.

Ursul, Arkady and Tatiana Ursul. Environmental Education for Sustainable Development. Future Human Image, Volume 9, 2018: 115-125. DOI: 10.29202/fhi/9/12 